\title{
"Creación de un tribunal de cuentas en la Comunidad Andina: experiencia de la Unión Europea"
}

Fernando Palomino Pella Asesora: Luzmila Zapata García

\section{Objetivos de la investigación}

En las sociedades democráticas, toda fiscalización es necesaria con el objeto de contar con la información pública y exacta que sirva de base a los procesos de debate y adopción de decisiones tendentes a promover el desarrollo equilibrado y armónico de los países miembros, acelerar su crecimiento y facilitar su participación en el proceso de integración.

Por ello, considerando que en la Comunidad Andina (CAN) no se ha instituido hasta la fecha un órgano de fiscalización, se decidió investigar y poner en debate serias irregularidades provenientes de la carencia de sistemas de transparencia pública. A través de esta tesis se expone la necesidad impostergable de contar con un tribunal de cuentas en la CAN - similar y tan importante como el existente en la Unión Europea (UE) -, con el que se logrará, incuestionablemente, empoderar a nuestros gobernantes y ciudadanos comunitarios en general, respecto a la urgente necesidad de contar con aquel.

Así, la propuesta de un tribunal de cuentas en la CAN permitirá el efectivo control y rendición de cuentas de los órganos e instituciones del Sistema Andino de Integración (SAI), previsto en el Acuerdo de Integración Subregional (AIS) (por ejemplo: Corporación Andina de Fomento, Fondo Latinoamericano de Reservas, Secretaría General, etc.), con lo 
que dicho tribunal se convertirá en un celoso vigilante del adecuado uso de los fondos públicos comunitarios frente a nuestros pueblos, a efectos de lograr los objetivos y fines del Acuerdo. No es posible concebir la democracia sin procedimientos eficientes de fiscalización.

\section{Metodología del trabajo}

Para el desarrollo de la tesis se empleó el método deductivo: a partir de premisas relativas a aspectos generales de la investigación, se arribó a situaciones particulares. Se recurrió a fuentes directas de información: entrevistas a funcionarios de la CAN (Secretaría General, Parlamento Andino), de la UE (Tribunal de Cuentas, Comisión), servidores domésticos, como el gerente de Cooperación Técnica de la Contraloría General de la República, y funcionarios diplomáticos en el contexto de foros académicos en la SG-CAN. Adicionalmente, se consultó copiosa bibliografía, en diferentes idiomas, a fin de tener la información precisa sobre la materia.

\section{Planteamiento del problema}

La tesis desarrollada se sustentó en la problemática y perfeccionamiento del SAI, previsto en el artículo 5 del AIS (conocido como Acuerdo de Cartagena), el que carece de un órgano o institución que controle los fondos financieros de la CAN, que se encargue de realizar auditorías periódicas a efectos de fiscalizar y mejorar la transparencia de las actividades e imagen eficiente de la organización supranacional andina, tanto en lo interno como en lo externo.

Ante este escenario, se consideró relevante examinar con profundidad el desenvolvimiento y éxito que tiene el Tribunal de Cuentas de la UE a fin de lograr que el Perú proponga, dentro del marco del Consejo Presidencial Andino, del Consejo Andino de Ministros de Relaciones Exteriores o de la Comisión, un tribunal de cuentas como órgano del SAI, en aras de la transparencia y mejor administración de los fondos que demandan los ciudadanos comunitarios. Un tribunal que ejerza de guardián independiente de los intereses financieros de los pueblos.

\section{Resumen de capítulos}

La tesis cuenta con seis capítulos. En el primero se desarrolla el concepto, evolución e importancia del derecho de la integración o derecho 
comunitario para el bien común de los pueblos, teniendo como objetivo elevar el nivel de vida de los ciudadanos. En el segundo capítulo se desarrolla la relevancia de la fiscalización, teniendo presente que la función fiscalizadora denota el sometimiento de la actividad socioeconómica del sector público a los principios universales de transparencia y legalidad. No es posible concebir la fiscalización sin una autonomía financiera indisociable de un control democrático del presupuesto. Gran parte de los recursos sobre los cuales se cimenta económicamente un gobierno u organización supranacional proviene del dinero que cada ciudadano aporta a través de sus impuestos. A manera ilustrativa, la tesis trata el exitoso caso del Panel de Fiscalización del Banco Mundial. Cuando se concibió el Panel de Inspección, la idea de un mecanismo de responsabilidad y transparencia con base ciudadana que empoderara a la gente local permitió a los pueblos alzar su voz en búsqueda de una revisión independiente de sus derechos.

En el tercer capítulo se expone la creación y avance de la UE como primer proceso (el mejor) en el planeta, sujeto al derecho de la integración. Repasando cada uno de los diferentes tratados que formaron y forman parte de ella, desde el Tratado Constitutivo de la Comunidad Europea del Carbón y del Acero, en 1952, hasta el Tratado de Lisboa, en 2009. Luego, en el cuarto capítulo, se expone la importancia del Tribunal de Cuentas en el éxito de la UE. Dicha institución fue creada el 22 de julio de 1975 mediante el "Tratado que modifica algunas disposiciones financieras", que entró en vigor el 1 de junio de 1977. Tiene su sede en Luxemburgo. Trabaja estrechamente con el Parlamento Europeo, el Tribunal de Justicia y la OLAF (Oficina de Lucha contra el Fraude). El motivo de su creación fue la necesidad de mejorar los niveles de fiscalización, teniendo especial importancia en el desarrollo evolutivo del proceso de integración en la UE.

Finalmente, en los capítulos quinto y sexto se desarrolla la problemática de la Comunidad Andina, donde se identifican los principales obstáculos que impiden que avancemos hacia mejores procesos de integración:

1. Reducido aporte económico de los países miembros a la CAN.

2. Inexistencia de presupuestos aprobados para los órganos e instituciones del SAI.

3. Inejecución y falta de supervisión de las donaciones y proyectos financiados por la UE. 
4. Falta de aplicación de mecanismos de transparencia y control financiero.

5. Presuntas irregularidades descubiertas en torno a la deficiente gestión del presupuesto en la CAN. 